\title{
Reupl RECORUCUNi
}

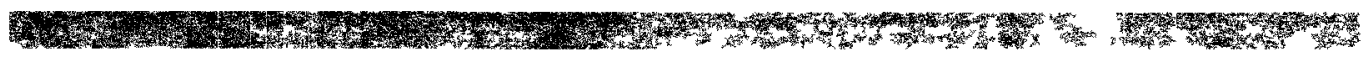

REPORT NO. RN-S-0179
\end{abstract}

TO

AEC-NASA SPACE NUCLEAR PROPULSION OFFICE

PRE-IRRADIATION ANALYSIS OF

TUNGSTEN-RHENIUM THERMOCOUPLES (U)

Contract SNP-I December $1964 \quad$ NERVA Program

RECORD COPY

.

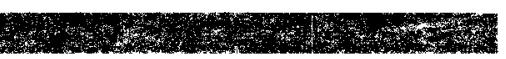

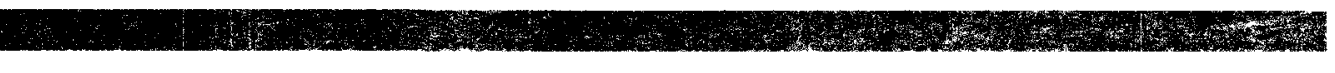




\section{DISCLAIMER}

This report was prepared as an account of work sponsored by an agency of the United States Government. Neither the United States Government nor any agency Thereof, nor any of their employees, makes any warranty, express or implied, or assumes any legal liability or responsibility for the accuracy, completeness, or usefulness of any information, apparatus, product, or process disclosed, or represents that its use would not infringe privately owned rights. Reference herein to any specific commercial product, process, or service by trade name, trademark, manufacturer, or otherwise does not necessarily constitute or imply its endorsement, recommendation, or favoring by the United States Government or any agency thereof. The views and opinions of authors expressed herein do not necessarily state or reflect those of the United States Government or any agency thereof. 


\section{DISCLAIMER}

Portions of this document may be illegible in electronic image products. Images are produced from the best available original document. 


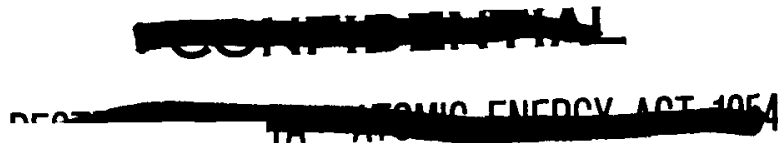

NOTICE

This report was prepared as an account of work sponsored by the United States Government. Neither the United States nor the United States Energy Research and Development Administration, nor any of their employees, nor any of their contractors, subcontractors, or their employees, makes any warranty, express or implied, or assumes any legal liability or responsibility for the accuracy, completeness or usefulness of any information, apparatus, product or process disclosed, or represents that its use would not infringe privately owned rights.

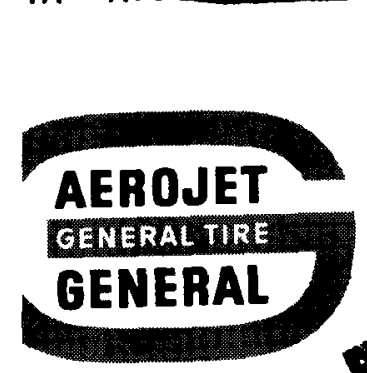

\section{MASTER}

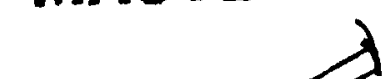

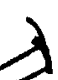

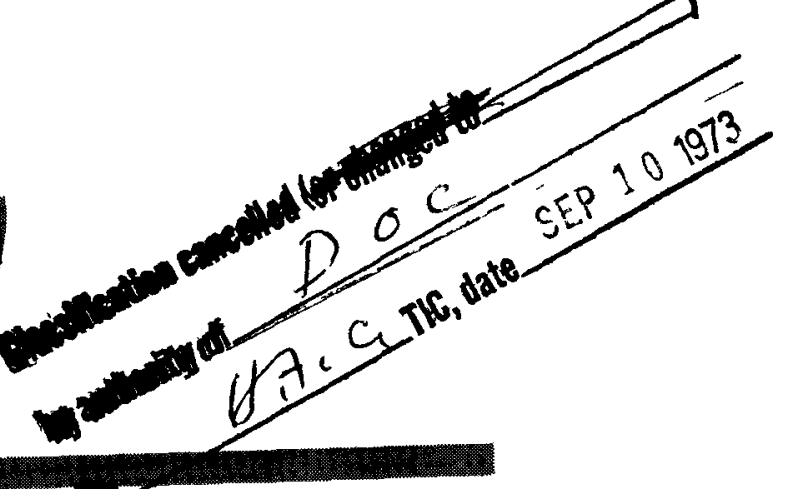

w)
REPORT NO. RN-S 0179

TO

AEC-NASA SPACE NUCLEAR PROPULSION OFFICE CONTRACT SNP-I DECEMBER 1964 NERVA PROGRAM

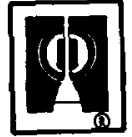

ROCKET ENGINE OPERATIONS - NUCLEAR

PRE-IRRADIATION ANALYSIS OF

TUNGSTEN-RHENIUM THERMOCOUPLES (U)
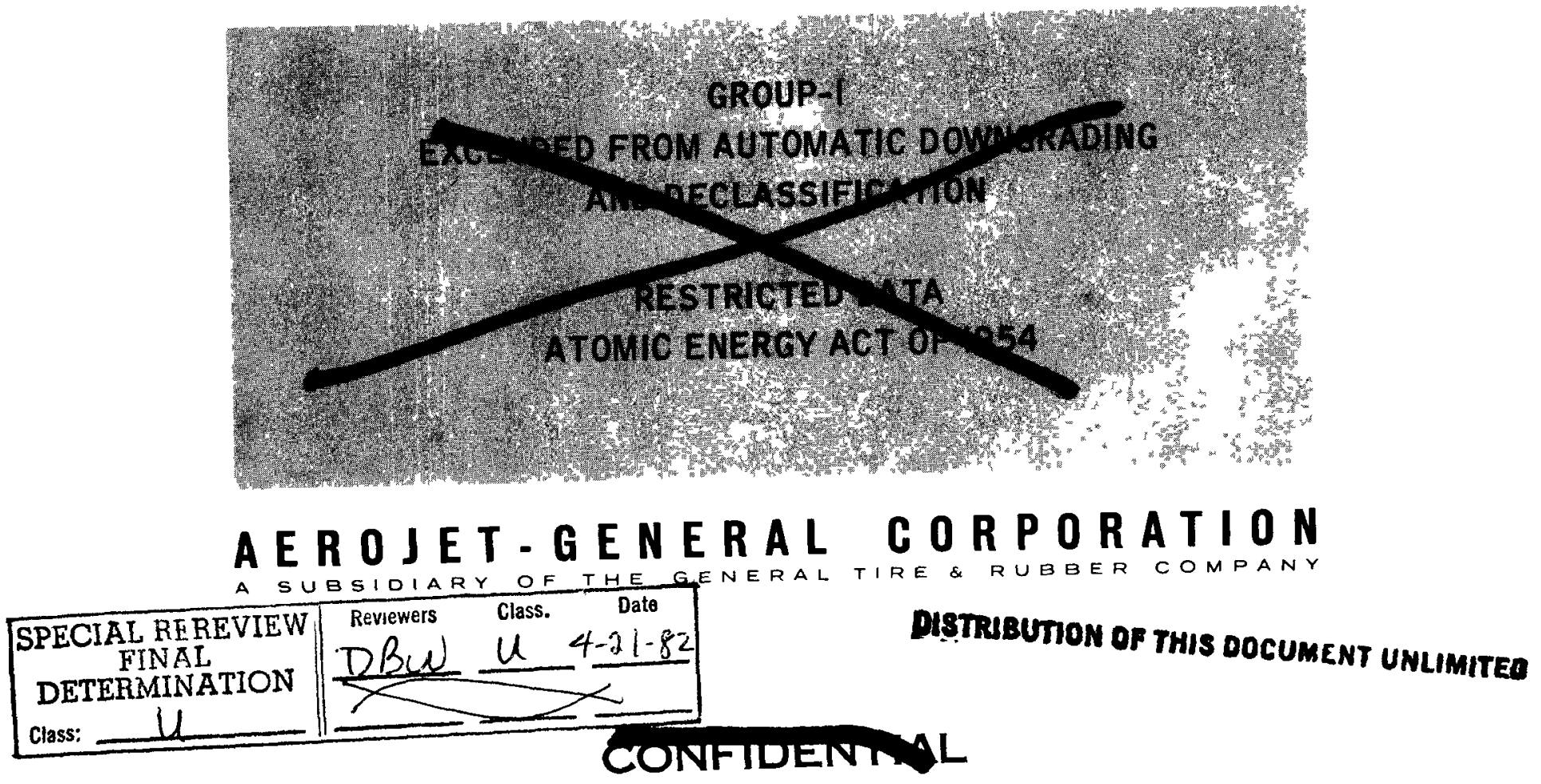


\section{ABSTRACT}

Thungsten-rhenium thermocouples were analyzed for their expected performance in a radiation field. All components of the thermocouples are inorganic, and their limitations are based on a long-term degradation. The degradation in full-power, full-duration NERVA firings is negligible. It was found that the largest temperature discrepancy will be caused by radiant energy dissipation to the cryogenic surface which the thermocouple penetrates. The discrepancy will be $54^{\circ} \mathrm{F}$ at full power, and should be regarded as a correction to be applied to read-out values.

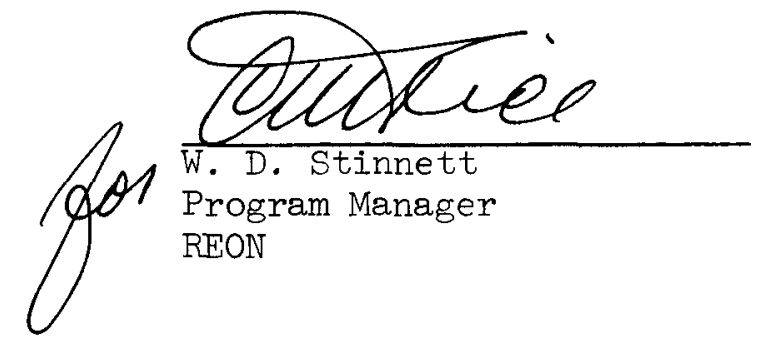




$\begin{array}{llr}\text { I } & & \text { PAGE } \\ \text { II } & \text { CONCLULYSIS OBJECTIVE } & 1 \\ \text { III } & \text { SUBJECT DESCRIPTION } & 1 \\ & \text { A. } \quad \text { GENERAL } & 1 \\ \text { B. } \quad \text { BASIC PROPERTIES OF TUNGSTEN-RHENIUM } & 1 \\ & \text { THERMOCOUPLES } & 1 \\ \text { IV } & \text { ANALYSIS } & 2 \\ & \text { A. RADIATION COMPATIBILITY OF MATERIALS } & 2 \\ & \text { B. THERMODYNAMIC AND GAMMA HEATING ERRORS } & 2 \\ & \text { AND CORRECTIONS } & 13 \\ \text { C. NEUTRON ABSORPTION EFFECTS } & 20 \\ \text { D. } & \text { EFFECT OF INSULATION BREAKDOWN ON } \\ \text { REFERENCES } & \text { THERMOCOUPLE PERFORMANCE } \\ \text { APPENDIX I } & \text { RELATED RADIATION TESTS } & 21 \\ \text { APPENDIX II } & \end{array}$




\section{LIST OF FIGURES}

FIGURE

NUMBER

1

THERMOCOUPLE, IMMERSION - TUNGSTEN WITH FIVE PERCENT RHENIUM VS TUNGSTEN WITH TWENTY-SIX PERCENT RHENIUM, AGC DRAWING NO. 701571 THRU 701580

2. THERMOCOUPLE, IMMERSION - TUNGSTEN WITH FIVE PERCENT RHENIUM VS TUNGSTEN WITH TWENTY-SIX PERCENT RHENIUM, AGC DRAWING NO. 701515 THRU 701524

3

TEMPERATURE CORRECTION FOR BeO W/Re THERMOCOUPLES

4

TEMPERATURE CORRECTION FOR HEIIUM FIILED W/Re THERMOCOUPLES

5

THERMAL EMF OF TUNGSTEN TWENTY-SIX PERCENT RHENIUM THERMOCOUPLES

6

CHANGE IN EMF WITH PERCENT CHANGE IN RHENIUM AS A FUNCTION OF TEMPERATURE, W/26\% RHENIUM THERMOCOUPLES

ELECTRICAL CONDUCTIVITY AS FUNCTION OF RADIATION DOSE RATE AND TEMPERATURE

ELECTRICAL CONDUCTIVITIES OF CERAMIC INSULATORS 
The basic purpose of the analysis was to estimate the radiation tolerance of tungsten-rhenium thermocouples and to estimate their performance in the NERVA environment.

\section{CONCLUSIONS}

The expected behavior of tungsten-rhenium thermocouples in the NRX-A2 radiation field has been investigated. The gamma heating, neutron absorption effects, and cable insulation breakdown were considered from an analytical standpoint. Radiation effects were found to be negligible with respect to radiant energy effects and to the required accuracy limits. The cable insulation breakdown is open to uncertainty and should be substantiated by tests to insure that the induced conductivity is no greater than was assumed.

\section{SUBJECT DESCRIPTION}

A. GENERAL

The tungsten-rhenium sheathed-type thermocouples being manufactured for use on NRX-A2, consist of two basic designs with minor variations in shape for mounting on various nozzles. One concept has a helium-filled probe for insulation and the other has hard-packed beryllium oxide for insulation. The sensing elements are $W-W / 26 \%$ Re or $W / 5 \%$ Re $-W / 26 \% \operatorname{Re}$. The construction of the thermocouples is shown in Figures 1 and 2 (Reference 1 ).

The accuracy requirements for the temperature readings in NRX-A2 are $\pm 80^{\circ} \mathrm{F}$.

\section{B. BASIC PROPERTIES OF TUNGSTEN-RHENIUM THERMOCOUPLES}

Tungsten/tungsten-rhenium thermocouples are being developed to sense the nozzle temperatures of the NERVA engine and are ultimately scheduled to become control sensors. They have been used in the Kiwi reactor program.

Tungsten does not react with hydrogen up to its melting temperature (Reference 2).

Errors may be introduced in thermocouple readings because of gas thermodynamics and gamma heating, neutron absorption effects, and radiation effects on associated circuits. The expected errors in the NRX-A2 environment are discussed in this report. 
IV ANALYSIS

A. RADIATION COMPATIBILITY OF MATERIAIS

The materials of construction of the thermocouples are tungsten, rhenium, BeO, MgO, Type 347 stainless steel, and helium. All the materials are inorganic and radiation resistant within the limits specified in this report. Embrittlement of tungsten has been found to occur upon irradiation at higher dosages than encountered in NRX-A2, but this would cause no particular trouble other than fragility for the function it serves in thermocouple applications.

B. THERMODYNAMIC AND GAMMA HEATING ERRORS AND CORRECTIONS

If a thermocouple is used to measure gas temperatures, the sources of error and the necessary corrections that must be added may originate from several sources. Consideration of the collective effects is necessary. The effects include the following:

\section{Adiabatic Gas Effects}

If the measurement is made in high-velocity gas streams, the gas will be brought to rest at the probe surface. The gas temperature to which the probe is subjected is less than the stagnation temperature of the gas and is given by

$$
T_{\text {aw }}=r\left(T_{0}-T_{s}\right)+T_{s} \quad \text { where }
$$

$r=$ the recovery factor which represents the efficiency of the stagnation effect

$\mathrm{T}_{\text {aw }}=$ the adiabatic wall temperature

$\mathrm{T}_{\mathrm{s}}=$ static temperature $=\mathrm{T}_{0}-\frac{v^{2}}{2 \mathrm{gJC}}$

$T_{0}=$ the original stagnation temperature of gas

$\mathrm{T}_{\text {aw }}$ is the maximum gas temperature that the thermocouple would be able to measure.

The recovery factors for flow normal to thermocouple wires were measured by several investigators and have varied from 0.63 to 0.66 for butt-welded thermocouples (Reference 3). 


\section{Convective Heat Transfer}

Heat is transmitted from the gas to the probe by forced convection according to

$$
\text { h A }\left(T_{g}-T_{p r}\right) \quad \text { where }
$$

$\mathrm{h}=$ convective heat transfer coefficient

$A=\pi D_{0} L$ (probe heat transfer area)

$D_{0}=$ probe diameter

$L=$ probe length

$T_{\text {aw }}=$ adiabatic wall temperature

$\mathrm{T}_{\mathrm{pr}}=$ probe surface temperature

The convective heat transfer coefficient* for cross-flow to a cylinder can be evaluated by

$$
\frac{\mathrm{h} \mathrm{D}_{\mathrm{o}}}{\mathrm{k}}=\left\{0.35+0.47\left(\frac{\mathrm{D}_{\mathrm{O}} \mathrm{G}}{\mu}\right)^{0.52}\right\}_{\mathrm{Pr}} 0.3 \quad \text { (Ref. 4) }
$$

where $k=$ fluid thermal conductivity

$G=$ fluid flow rate $(\rho v)$

$\mu=$ fluid viscosity

$\operatorname{Pr}=$ PrandtI number

\section{Radiant Heat Dissipation}

If the wall temperature is lower than the thermocouple temperature the thermocouple will give up heat to the wall. The expression governing this process is

$$
\begin{aligned}
& \left.\epsilon_{\mathrm{pr}, \mathrm{w}} \sigma_{\mathrm{A} r(\mathrm{~T}}{ }_{\mathrm{pr}}^{4}-\mathrm{T}_{\mathrm{w}}^{4}\right) \quad \text { where } \\
& T_{w}=\text { nozzle surface temperature } \\
& T_{p r}=\text { probe temperature } \\
& \sigma=\text { Stefan-Boltzman constant } \\
& \epsilon_{\text {pr, } w}=\text { equivalent emissivity of the probe and surface } \\
& \text { and is defined by }
\end{aligned}
$$

* Appendix I shows a comparison of heat transfer coefficient evaluated by two expressions.

$$
-3-
$$




$$
\begin{aligned}
& \quad \frac{1}{E_{p r, w}}=\frac{1}{E_{p r}}+\frac{A_{p r}}{A_{w}}\left(\frac{I}{E_{w}}-1\right) \text { where } \\
& E_{p r}=\text { thermocouple emissivity } \\
& E_{w}=\text { surface emissivity }
\end{aligned}
$$

Generally $A_{w} \gg A_{p r}$ and $\epsilon_{p r, w}=\epsilon_{p r}$. The above expression then becomes

$$
E_{p r} \sigma_{A p r}\left(T_{p r}^{4}-T_{w}^{4}\right)
$$

\section{Gamma Heating}

Heat is generated throughout the probe if it is in a

nuclear field. In this discussion $E_{\gamma}$ is the total gamma energy generated in the probe in BTU/hr.

\section{Heat balances which included the foregoing effects were} performed for the two versions of the tungsten-rhenium thermocouple shown in Figures 1 and 2 .

The sensing element of one design (Figure 1) consists of a tungsten-26\% rhenium tube which acts as one leg of the thermocouple. The inner leg is a 40-mil tungsten-5\% rhenium wire. The separation of the two is affected by filling the concentric area between them with helium (15 psig at $77^{\circ} \mathrm{F}$ ). The junction is considered proprietary by the manufacturer. For heat transfer and error analysis purposes it was assumed that the junction is made by a contact of the surface of the wire with a 0.030-in. tungsten-5\% rhenium end cap.

The probe of the second version, which is a grounded type, consists of a tungsten/26\% rhenium tube which contains two 15-mil thermocouple wires of tungsten/5\% rhenium and tungsten/26\% rhenium. The insulation is hard packed beryllium oxide. In this report the versions are distinguished by their insulation; either helium filled or beryllium-oxide type. 
Both probes have a 0.145 inch diameter and have immersion lengths of about 1.5 inches. The probes are to be located in the converging section of the NRX-A2 nozzle at 8.9 expansion ratio and will sense the gas temperature by extending 1.5 inches into the stream. The gas temperature and thermocouple discrepancies will be functions of reactor power level, hence the results are presented as a function of gas temperature. The relationship between temperature and power level may be found in Reference 5.

The conduction errors were assessed on a worst-case basis, independently of the other effects, to determine their maximum contribution. This was done because of the complication conduction adds to the general case. The thermal analysis program of the digital computer that was used to evaluate temperature distributions for stress purposes, showed that the base temperature of the probe will remain considerably above the nozzle wall temperature at the penetration point. Maximum conduction would occur if the probe temperature were equal to the wall temperature at the penetration point. The ranges of junction temperature deficiencies below the adiabatic wall temperature on a maximum conduction basis were found to be between $0.4^{\circ} \mathrm{F}$ and $0.8^{\circ} \mathrm{F}$ at $700^{\circ} \mathrm{R}$ gas temperature, $0.03^{\circ} \mathrm{F}$ and $0.11^{\circ} \mathrm{F}$ at $1000^{\circ} \mathrm{R}$ gas temperature, and negligible for higher gas temperatures and flow rates.

The heat balance for convection, radiant heat emission, and gamma heating is:

$$
h\left(T_{a w}-T_{p r}\right) A_{p r}+E_{\gamma}=E O\left(T_{p r}^{4}-T_{w}^{4}\right) A_{p r}
$$

or

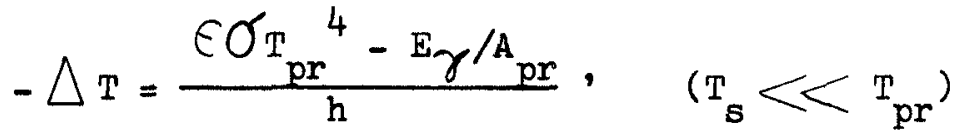

The full-power gamma field in which the probe is located was taken as 1.25 watts/gram (C) or $4.27 \mathrm{BTU} / \mathrm{gm}(\mathrm{C})-\mathrm{hr}$ 。

The thermal transport properties which were used in the evaluation of the heat transfer coefficients are given in Appendix I. 
The gamma heating, causes a small difference in the probe temperature. However, gamma heating introduces gradients and uncertainties in the helium probe because the heat generated must be conducted across the gas layer. The maximum gradient in the BeO model from the center to the outside will be $1^{\circ}$, based on an average thermal conductivity. This represents the maximum difference that can exist between the thermocouple junction and the probe surface.

The temperature corrections or deficiencies that were computed for each thermocouple are given in Tables $I$ and II. The values at $3200^{\circ} \mathrm{R}$ and $4090^{\circ} \mathrm{R}$ were computed for the same propellant flow rate. A comparison of columns IV and $V$ shows the contribution of gamma heating. The last two columns (VIII and IX) indicate the total deficiencies that the thermocouple will experience. For example, if the gas stagnation temperature is $3200^{\circ} \mathrm{R}$, the helium model thermocouple will read between $3183^{\circ} \mathrm{R}$ and $3193^{\circ} \mathrm{R}$, based on the thermal considerations only. Plots of the results of Tables I and II are shown in Figures 3 and 4.

C. NEUTRON ABSORPTION EFFECTS

Consideration of irradiation periods and fluxes and nuclear cross-sections, half-lives, and the effect of changes in composition of the basic components on thermocouple output is necessary to estimate the effect of transmutation on thermocouple accuracy.

The cross-sections and half-lives of the isotopes of tungsten and rhenium are shown in Table III (Reference 6). 
TABLE I

TEMPERATURE DISCREPANCY OF W/Re THERMOCOUPLES AT NOZZLE EXPANSION RATIO 8.9 IN NRX-A2 Helium-Filled Model

\begin{tabular}{|c|c|c|c|c|c|c|c|c|c|c|}
\hline $\begin{array}{l}\text { Stagnatio } \\
\text { Temp. }\end{array}$ & & I & II & III & IV & v & VI & V.II & VIII & IX \\
\hline$T_{0}$ & $\epsilon$ & $\mathrm{h}$ & $\mathrm{T}_{\mathrm{aw}}$ & $\epsilon \sigma T^{4}$ & $\triangle \mathrm{T}$ & $\Delta \mathrm{T}$ & $\Delta \mathrm{T}$ & $\Delta_{\mathrm{T}}$ & Net & $\begin{array}{l}\text { Possible } \\
\text { Additional }\end{array}$ \\
\hline${ }^{\circ} \mathrm{R}$ & & $\begin{array}{l}\mathrm{BTU} / \mathrm{Hr}- \\
\mathrm{ft}^{2}-{ }^{\circ} \mathrm{F}\end{array}$ & ${ }^{\circ} \mathrm{R}$ & $\mathrm{BTU} / \mathrm{hr}-\mathrm{ft} \mathrm{t}^{2}$ & $\begin{array}{l}\text { Thermal } \\
\text { Radiation }\end{array}$ & $\begin{array}{l}\text { Combined } \\
\text { Thermal } \\
\text { \& Gamma }\end{array}$ & $\begin{array}{c}\text { Adiabatic } \\
\text { Loss }\end{array}$ & $\begin{array}{l}\text { Conduction } \\
\text { Loss }\end{array}$ & $\Delta \mathrm{T}$ & $\Delta \mathrm{T}^{*}$ \\
\hline
\end{tabular}

\begin{tabular}{|c|c|c|c|c|c|c|c|c|c|c|}
\hline 700 & .03 & 268 & 699.8 & 12 & 0.05 & -0.02 & 0.2 & +0.08 & +0.26 & -0.4 \\
\hline 1000 & .05 & 540 & 999.8 & 86 & 0.16 & -0.34 & 0.2 & +0.10 & -0.04 & -0.14 \\
\hline 1500 & .08 & 873 & 1499.6 & 696 & 0.80 & +0.06 & 0.4 & $\ldots$ & +0.64 & -2.6 \\
\hline 2000 & .11 & 1251 & 1999.5 & 3163 & 2.5 & +1.4 & 0.5 & $\ldots$ & +1.9 & -4.7 \\
\hline 2400 & .15 & 1609 & 2399.4 & 8566 & 5.3 & 4.0 & 0.6 & $\ldots$ & 4.6 & -6.4 \\
\hline 2800 & .20 & 1914 & 2799.3 & 21140 & 11.0 & 9.5 & 0.7 & $-\ldots$ & 10.2 & -8.5 \\
\hline $3200 * *$ & .23 & 2248 & 3199.2 & 41510 & 18.5 & 16.6 & 0.8 & 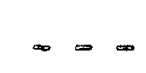 & 17.4 & -9.8 \\
\hline $4090 * *$ & .29 & 2539 & 4089.0 & 139700 & 55.0 & 53.0 & 1.0 & -- & 54.0 & -10.8 \\
\hline
\end{tabular}

* Uncertainty caused by dissipation of gamma heat from inner wire across helium annulus.

** Same nozzle gas flow rate. 
TABLE II

TEMPERATURE DISCREPANCY OF W/Re THERMOCOUPLES AT NOZZLE EXPANSION RATIO 8.9 IN NRX-A2 Beryllium Oxide Model

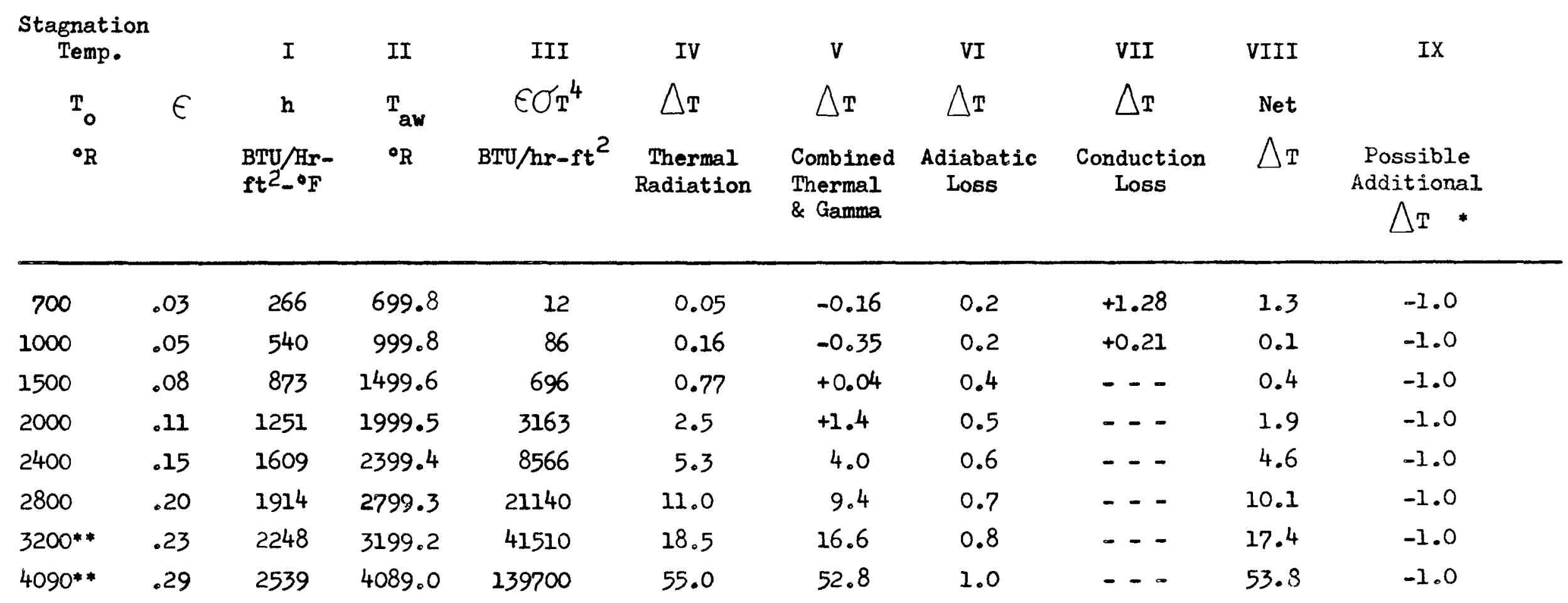

* Uncertainty caused by probe gradients introduced by gamma heating.

** Same Nozzle Flow Rate。 
TABLE III

\section{THERMAL NEUTRON CROSS-SECTIONS AND HALF-LIVES} OF TUNGSTEN AND RHENIUM ISOTOPES

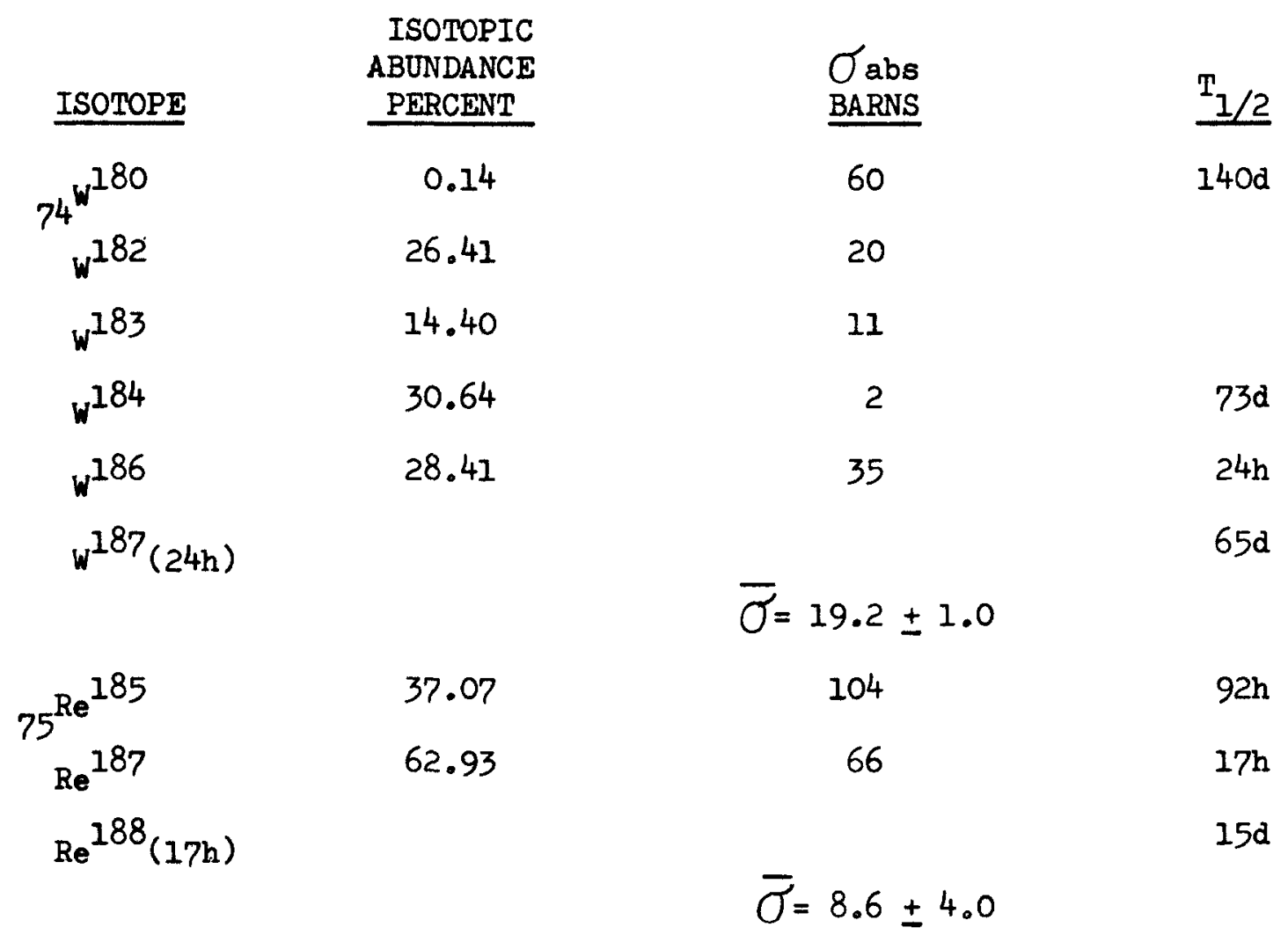

In addition, $\operatorname{Re}^{185}$ has a 3500 barn resonance cross-section at 2.18 ev and $\operatorname{Re}^{187}$ has a 370 barn resonance at $4.4 \mathrm{ev}$. The calculated resonance integrals from .52 ev to fission energy are 1630 and 310 barns respectively (Reference 7)。

The transmutation products of tungsten and rhenium are rhenium. and osmium. The effect of osmium on the thermoelectric power of the thermocouples is not known. However, curves which show the effect of percentage composition of rhenium on the thermal emf of tungsten-rhenium thermocouples were published in Reference 8. The values of emf vs temperature and ( $\triangle \mathrm{emf} / \triangle \% \mathrm{Re}$ ) for tungsten/26\% rhenium thermocouples as a function of 
temperature are shown in Figures 5 and 6 . Figure 6 was obtained by taking the slopes of emf vs weight percentage of rhenium for various temperatures. The calculated neutron effect on thermocouple performance was based on rhenium depletion. The effect of neutron capture in tungsten and the presence of osmium were neglected. These effects are regarded as secondary to rhenium depletion. The neutron effect on performance during irradiation, and the effect on performance after long decay periods were calculated by the following considerations.

The number of activated atoms formed during an irradiation period, $t$, is:

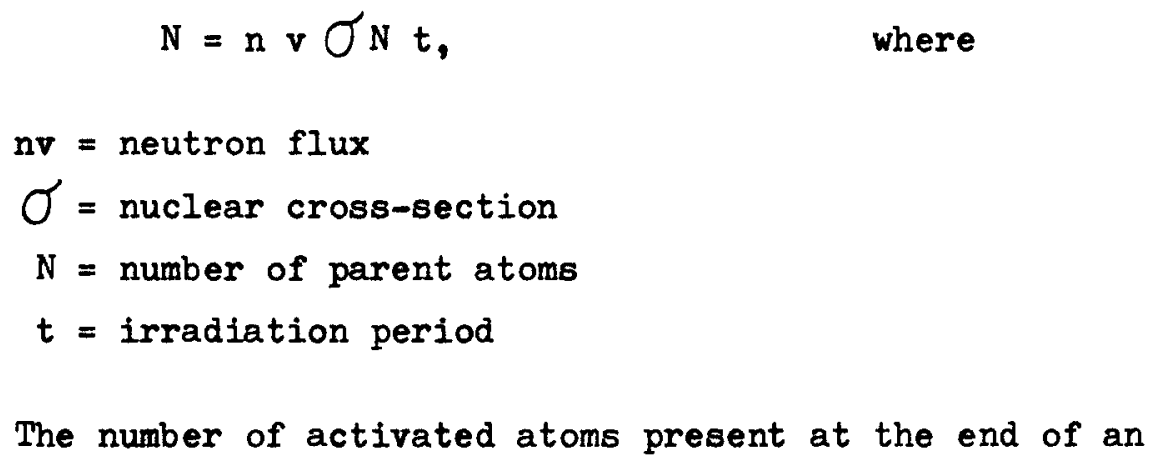

$$
\begin{gathered}
\mathrm{N}_{\mathrm{a}}=\frac{\mathrm{nv \sigma} N}{\lambda}\left(1-\mathrm{e}^{-\lambda t}\right), \quad \text { where } \\
\lambda=\text { decay period }=.693 / \mathrm{T}_{1 / 2}
\end{gathered}
$$

The number of activated atoms that have decayed during the irradiation is:

$$
n v \sigma N\left(t-\frac{1-e^{-\lambda t}}{\lambda}\right)
$$

This value represents the change in content of the parent material during irradiation. 
The percentage change in rhenium can be estimated by considering thermal and fast neutrons and using the resonance integral with the fast flux. The general expression for change in content during irradiation is:

$$
\begin{aligned}
& \% \frac{\Delta \operatorname{Re}}{\operatorname{Re}}=f_{1}\left(\sum_{j, j}\left(n v \sigma_{1}\right)_{i}\left(t-\frac{1-e^{-\lambda_{1} t}}{\lambda_{1}}\right)+f_{2}\left(\sum_{i, j}\left(n v \sigma_{2}\right)_{i} \cdot\right.\right. \\
& \left(t-\frac{1-e^{-\lambda_{2} t}}{\lambda_{2}}\right)
\end{aligned}
$$

where subscripts 1 and 2 refer to the two isotopes of rhenium, and $f$ and $\lambda$ are their isotopic fractions and decay constants. The values $i$ and $j$ refer to fast and thermal neutron groups.

The change of content as a result of irradiation for a period, $t$, and a decay period of time sufficient for the activated atoms to have changed into decay products is:

$$
\% \frac{\Delta_{R e}}{\operatorname{Re}}=f_{1} \quad \sum_{i, j}\left(n v \sigma_{1}\right)_{i} t+f_{2} \sum_{i, j}\left(n v \sigma_{2}\right)_{i} t_{0}
$$

The foregoing expressions were evaluated for a full-duration, full-power run of NRX-A2 in simultaneous thermal and fast neutron fluxes of $3 \times 10^{12}$ and $4 \times 10^{14}$ neutrons $/ \mathrm{cm}^{2}$-sec respectively. The thermal neutron effects were negligible compared to the fast neutron effects. The following values were obtained:

\begin{tabular}{lc} 
& $\begin{array}{r}\text { Change in Rhenium Content } \\
\% \triangle \operatorname{Re} / \operatorname{Re}\end{array}$ \\
\cline { 2 - 2 } During irradiation & $9.48 \times 10^{-5}$ \\
Long decay period & $2.88 \times 10^{-2}$
\end{tabular}

The change in rhenium content $(\triangle \%$ Re) in a $26 \%$ rhenium thermocouple is a factor of 0.26 times these values. 
The change in output was obtained from these values multiplied by appropriate values ( $\triangle \mathrm{mv} / \triangle \% \mathrm{Re}$ ) of Figure 6 . The temperature error may be obtained from corresponding values of millivolt output $/{ }^{\circ} \mathrm{F}$ as functions of temperature (Figure 5).

It was found that the range of error at the end of a full-power, full-duration NRX-A2 irradiation will be between $5.0 \times 10^{-4}$. $\mathrm{R}$ at $960^{\circ} \mathrm{R}$ and $2.0 \times 10^{-3} \circ \mathrm{R}$ at $4500^{\circ} \mathrm{R}$.

A long decay period will result in a shift of the output curve so that the thermocouple would read low by the amounts shown in Table IV.

TABLE IV

ANTICIPATED CHANGE IN OUTPUT OF $W-W / 26 \%$ Re AS RESULT OF NRX-A2 IRRADIATION AND LONG DECAY PERIOD

\begin{tabular}{ll}
$\begin{array}{c}\text { Temp. } \\
\circ \mathrm{F}\end{array}$ & $\Delta \cdot \mathrm{F}$ \\
\hline 500 & .14 \\
1000 & .22 \\
1500 & .27 \\
2000 & .32 \\
2500 & .39 \\
3000 & .48 \\
3500 & .60 \\
4000 & .75
\end{tabular}

The calculated neutron effects of similar thermocouples in GTR-13, which was a 100-hour irradiation period in approximate fast and thermal fluxes of $7.6 \times 10^{11}$ and $2 \times 10^{12} \mathrm{n} / \mathrm{cm}^{2}-\mathrm{sec}$, respectively, were that a $1.5^{\circ} \mathrm{F}$ discrepancy would be introduced by the end of the irradiation period.

Calculations were performed for $W-W / 26 \%$ Re thermocouples because emf datawere available. The results would not differ significantly for $w / 5 \%$ $\operatorname{Re}-W / 26 \% \operatorname{Re}$. 
D. EFFECT OF INSULATION BREAKDOWN ON THERMOCOUPLE PERFORMANCE Combined effects of radiation and temperature on the insulation properties of materials must be assessed in order to obtain a known precision in temperature measurements.

Circuits and error curves for insulation leakage in thermocouple circuits are shown in Reference 9. A sketch of two of the circuits illustrates the nomenclature and resistances. The thermocouple circuit with no leakage and the same circuit with insulation leakage between the leads are shown.

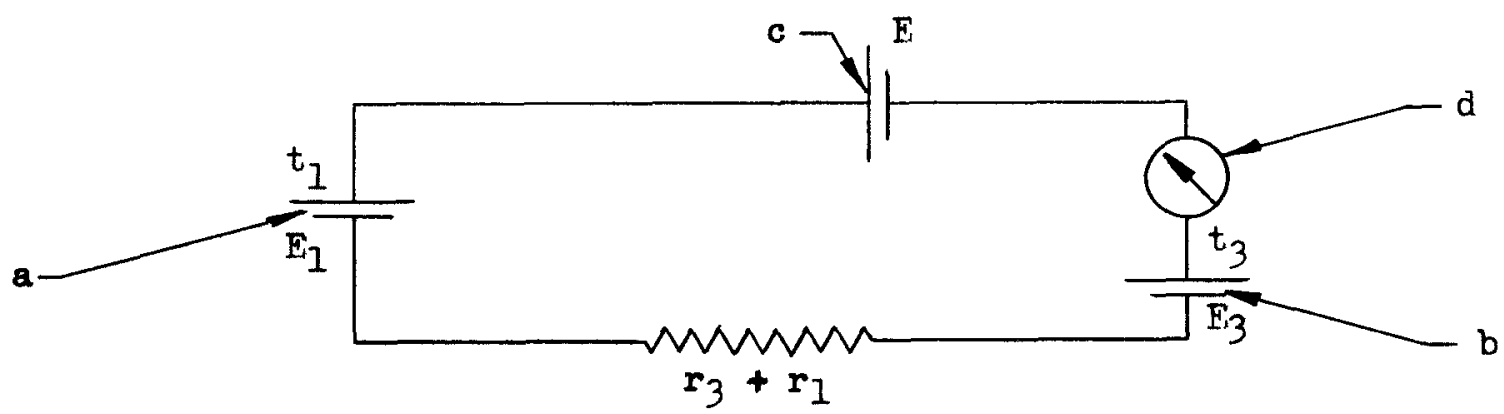

Thermocouple circuit without insulation leakage. a, "hot" junction;

$b$, "cold" junction; c, balancing emf; $d$, current indicator

a

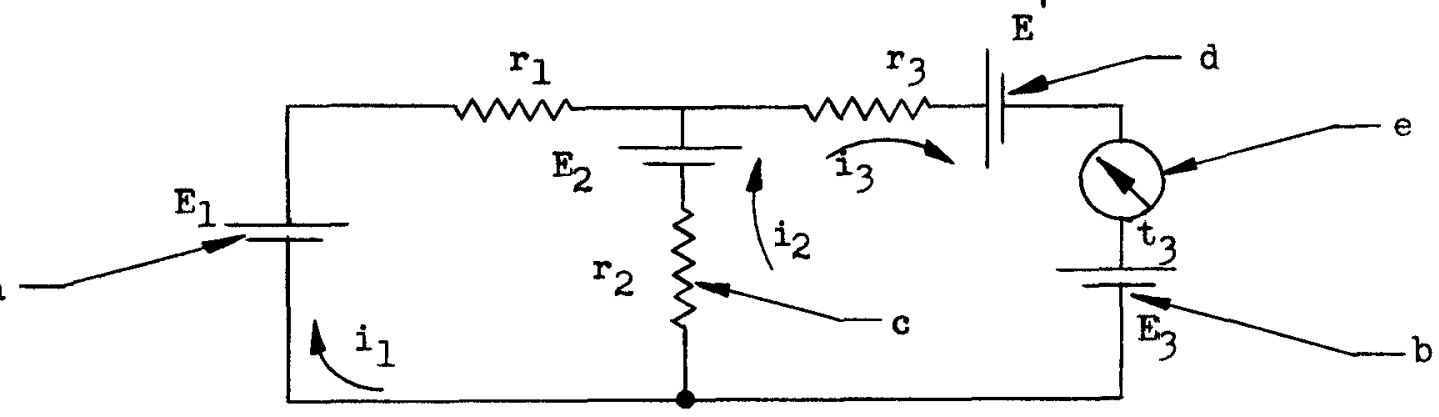

Same circuit with insulation leakage between leads. a, "hot" junction; b, "cold" junction; c, assumed insulation leakage; d, balancing emf; $e$, current indicator.

The percentage error is:

$$
\% \text { error }=\left(\frac{E-E^{\prime}}{E}\right) \quad(100)=\frac{t_{1}-t_{2}}{t_{1}-t_{3}}\left|\frac{1}{2+1}\right|(100)
$$


where

$$
\begin{aligned}
& a=r_{2} / r_{1} \\
& r_{2}=\text { short-circuit resistance } \\
& r_{1}=\text { lead resistance between hot junction and }
\end{aligned}
$$

The same relationship holds for circuits with insulation leakage between one lead and the parent metal at two points and with insulation leakage between both leads and the parent metal.

It can be demonstrated that insulation near the hot junction is relatively unimportant to thermocouple accuracy if the hot junction temperature is appreciably greater than the cold junction. For example, if insulation leakage occurs at the $3100^{\circ} \mathrm{R}$ point of a probe which is sensing $3300^{\circ} \mathrm{R}$ gas and whose cold junction is the ice point, $0.1 \%$ error will be introduced if "a" drops to 70 at the leakage point.

Conductivity can be induced in solid insulating materials by elevated temperature and by gamma radiation.

When insulating materials are subjected to gamma radiation, free electrons are produced which may be made to flow when a voltage is applied. The induced conductivity reaches equilibrium within a very short time after the irradiation begins and disappears rapidly when removed from the radiation field. According to Mayburg (Reference 10), classical electrodynamic theory postulated that the magnitude of the conductivity rise is a function of the rate of incident radiation and the strength of the electric field applied across the insulator. The limits of variation are: (1) low radiation rate and high electric field where all of the charge carriers produced are swept out, resulting in direct proportionality between equilibrium conductivity and radiation rate (slope of one in the expression $I Q R_{R} \Delta$, where $I$ is conductivity and $R$ is radiation dose rate), and (2) high radiation rate and low electric field where the charge carriers are produced at a faster rate than they can be swept away by the electric field. The accumulation of charges tends the slope toward a 
value of 0.5 . Fowler extended the theory to allow for individual differences of materials by postulating that each material has its own particular distribution of traps for radiation-excited electrons. Materials which have a $\triangle$ value of one (slope of the curve describing their conductivity versus radiation rate) possess a uniform distribution of traps.

Fowler and Huth determined the experimental values of $\triangle$ in the expression $I \propto{ }_{R} \Delta$ for inorganic insulators and found them to approach a value of one up to temperatures of $200^{\circ} \mathrm{F}$ in dose rates up to $10^{6} \mathrm{r} / \mathrm{hr}$ 。 Higher temperature behavior $\left(400^{\circ} \mathrm{F}\right)$ showed a decrease in slope. Huth attributed this to the magnitude of the dark current being increased by a much greater factor due to temperature rather than induced current.

Huth investigated the properties of alumina (Alsimag 614), fused quartz, and statite (Alsimag 196) $\mathrm{MgO}^{\circ} \mathrm{SiO}_{2}$ up to radiation rates of $5 \times 10^{5}$ $\mathrm{r} / \mathrm{hr}$. The results demonstrate the effect of combined radiation and temperature on the conductivity of solid insulators; they are shown in Figure 7. Unirradiated values of conductivity were $10^{-16}(\mathrm{ohm}-\mathrm{cm})^{-1}$ at room temperature。

The effect of temperature on conductivity for both $\mathrm{BeO}$ and $\mathrm{MgO}$ is shown in Figure 8 (References 11 and 12). The values vary, depending upon the experimenter, because methods of preparation and characteristics of different formulations vary widely。

Data for the effects of combined temperature and radiation on $\mathrm{BeO}$ and MgO properties could not be located. However, on the basis of theory and insight gained from experimental results of similar materials, several general statements of expected behavior in NRX-A2 can be made:

1. In the tungsten-rhenium thermocouples BeO will be in a high temperature region, therefore the conductivity will be predominately affected by temperature; the radiation effects will be secondary。 
The hot junctions of the NRX-A2 tungsten-rhenium thermocouples are grounded to the metal sheath. An analysis of secondary emfs in the insulation, caused by temperature effects in the hot probe section, is virtually impossible. Therefore (although the gradients are not identical to those which are anticipated in NRX-A2), calibrations of each NRX-A2 thermocouple as functions of temperature are made for the corresponding NRX-A2 immersion lengths. The work is performed in the Aerophysics Laboratory of Aerojet-General Corporation. As previously discussed, the effect of radiation on the high temperature part of the probe is expected to be secondary. A quantitative value would have to be obtained by test.

2. MgO cables will extend through widely divergent radiation fields and, depending upon the surface to which they are attached, the temperatures may vary from cryogenic to $200^{\circ} \mathrm{F}$ or more. The extremes which cause variations in conductivity will be for high dose rates at low or ambient temperatures where radiation effects predominate, and at high temperatures in fields where thermal effects predominate.

Insulation breakdown of the $\mathrm{MgO}$ cables can introduce significant errors in the thermocouple values.

The W/Re thermocouple cable of $\mathrm{NRX}-\mathrm{A} 2$ has been routed down the instrument boom. The maximum radiation field will be at the nozzle penetration. The cable extends horizontally onto the boom and passes through a field of $3 \times 10^{10} \mathrm{ergs} / \mathrm{gm}(\mathrm{c})-\mathrm{hr}$ (.833 watts $/ \mathrm{gm}$ ), approximately ten feet from the thermocouple location.

If the statite curve (slope $=0.62$ ) shown in Figure 8 is considered typical for $\mathrm{MgO}$, an estimate of the error introduced in the reading may be obtained if a partial short is introduced at either location. The nominal unirradiated resistance between the cable leads is 100 megohms. The resistance could be expected to decrease by a factor of $2.4 \times 10^{3}$ in a field of $3 \times 10^{10} \mathrm{ergs} / \mathrm{gm}(\mathrm{C})-\mathrm{hr}$ and $3.5 \times 10^{3}$ in a field of $4.5 \times 10^{10} \mathrm{ergs} / \mathrm{gm}(\mathrm{C})-\mathrm{hr}$ by assuming that no loss of resistance occurs up to a dose rate of $10^{5} \mathrm{ergs} / \mathrm{gm}$ (C) $-\mathrm{hr}$. The estimated percentage errors caused by the foregoing assumptions are 
summarized in Table $V$. It is seen that the error is relatively insensitive to hot junction temperature in the range considered. The cold junction temperature was taken as the ice point. Equation 12 was used to evaluate the effect of a possible short. 


\section{TABLE V}

POSSIBLE ERRORS INTRODUCED BY CABLE SHORTS

\begin{tabular}{|c|c|c|c|c|c|c|c|c|c|}
\hline $\begin{array}{c}\text { Short } \\
\text { Location }\end{array}$ & $\begin{array}{c}\text { Field } \\
\text { ergs } / g m(C)-h r\end{array}$ & $\begin{array}{c}\text { Assumed } \\
\text { Cable } \\
\text { Short } \\
\text { Temp }{ }^{\circ} \mathrm{F} \\
\end{array}$ & $\begin{array}{l}\text { Lead } \\
\text { Length } \\
\text { Feet } \\
\end{array}$ & $\begin{array}{c}\text { Cable } \\
\text { Resistance } \\
\text { Ohms }\end{array}$ & $\begin{array}{c}\text { Shorted } \\
\text { Resistance } \\
\text { Ohms }\end{array}$ & $\begin{array}{c}\text { "a" } \\
\text { (Eq. 12) }\end{array}$ & $\begin{array}{r}\mathrm{P} \\
\mathrm{Hot} \\
4090^{\circ} \mathrm{R} \\
\end{array}$ & $\begin{array}{l}\text { rcent Er } \\
\text { Junction } \\
3500^{\circ} \mathrm{R} \\
\end{array}$ & $\begin{array}{l}\text { or } \\
\text { Temp } \\
2000^{\circ} \mathrm{R}\end{array}$ \\
\hline A & $4.5 \times 10^{10}$ & 68 & 0.5 & .37 & $3.25 \times 10^{4}$ & $8.8 \times 10^{3}$ & .01 & .01 & .01 \\
\hline B & $3 \times 10^{10}$ & 200 & 10.0 & 6.0 & $4.2 \times 10^{4}$ & $7 \times 10^{3}$ & .01 & .01 & .01 \\
\hline
\end{tabular}


As shown in Table $V$, the percentage errors for the values which are believed to be typical for NRX-A2 are negligible. However, if the slope of the radiation-conductivity curve is taken as unity in Table $V$, the percentage error increases to $0.6 \%$. A factor of ten in the reduction of the conductivity would increase these errors to $0.1 \%$ and $6 \%$. (In actual practice the initial point on the conductivity-dose rate curve may not be at $10^{5}$ ergs/gm(C)-hr.)

Because of these factors a knowledge of the conductance of the cable as functions of field and temperature is vital in assessing probable errors of thermocouples in high radiation environments.

The presence of water vapor and the lack of symmetry in the spacings of the conductors, with respect to each other and to the cable sheath, can also introduce variations in conductivity.

In the absence of actual data the best preventive measures are to keep the conductor resistance low and the unirradiated insulation resistance as high as possible. Values of tungsten-rhenium lead wire resistances are given in Appendix IT.

$$
\text { 3. Helium, as an insulator in the tip of the helium-type }
$$
probe, will be affected by radiation. The ionizing potential which is the energy required to remove the most loosely bound electron in the gas molecule is 24.5 electron volts for helium. Measurements have shown that the average energy absorbed in helium per ion pair produced is 28 electron volts. Thus an incident gamma photon with $1.0 \mathrm{Mev}$ energy will produce $10^{6} / 28=3.6 \times 10^{4}$ ion pairs. The breakdown of insulation in the probe tip, as pointed out earlier, is not expected to introduce appreciable error because of the high temperature of the whole tip region. A comparison of the breakdown of gas insulation as opposed to solid insulation breakdown $c_{a} n$ best be achieved by intercomparison in combined temperature and radiation fields. A complete breakdown of either insulation will introduce errors which reflect the probe temperature gradient. 


\section{E. RELATED RADIATION TESTS}

Two tungsten-rhenium thermocouples were irradiated in GTR Test

No. 13 beginning 8 June 1964 (Reference 13). They were mounted in helium-purged heaters which were periodically energized so that the thermocouples were at approximately $2500^{\circ} \mathrm{F}$. One of the thermocouples failed 18.8 hours after initiation of the test. Although it registered outputs after its injtial malfunction, the data showed that it became progressively worse.

The output of the second thermocouple gradually decreased during the one-hundred hour test so that it read about $100^{\circ} \mathrm{F}$ lower at the end of the test than at the beginning. The degradation could not be attributed solely to radiation effects, and the test results were inconclusive. The integrated fast and thermal dosages were approximately $3 \times 10^{17}$ and $7 \times 10^{17} \mathrm{n} / \mathrm{cm}^{2}$ and the gamma dosage was approximately $10^{11} \mathrm{ergs} / \mathrm{gm}(\mathrm{C})$.

It was reported that four tungsten-rhenium thermocouples were used to measure the exit gas temperature of Kiwi-A3. Two were bare wire type, and two were sheathed type. All four survived the test and three of them agreed within 0.5\% (Reference 2). Tungsten-rhenium thermocouples were also used in the Kiwi-B-4D test of 13 May 1964. Except for generalities (Reference 14), the writer does not have access to the data at this time. 
1. Aerojet-General Corporation Specification Control Drawings 701571 through 701580 and 701515 through 701524 .

2. A. R. Driesner, et al, "High Temperature Thermocouples In The Rover Program," Los Alamos Scientific Laboratory, Paper presented at International Symposium on Aero-Space Nuclear Propulsion, Las Vegas, 25 October 1961.

3. Max Jakob, "Heat Transfer," John Wiley and Sons, 1962.

4. W. H. McAdams, "Heat Transmission," McGraw-Hill, 1942.

5. NRX-A2 Test Specification, Westinghouse Astronuclear Division, WANL-TNR-153, CRD (Title Unclassified), March 1964.

6. D. J. Hughes \& R. B. Schwartz, "Neutron Cross Sections," Brookhaven National Laboratory, BNL-325, 1 July 1958.

7. H. Soodak, "Reactor Handbook" Volume III, Part A, Interscience Publishers, 1962.

8. J. C. Lochman \& J. A. McGurty, "The Use of Refractory Metals for U1tra-High Temperature Thermocouples," published in "Temperature: Its Measurement and Control in Science and Industry," Volume III, Part 2, Reinhold Publishing Corporation 1962.

9. H. D. Baker, et al, "Temperature Measurement in Engineering," Volume $I_{\text {, }}$ John Wiley \& Sons, 1953, page 55.

10. Gerald C. Huth, "Conductivity Induced in Solid Insulating Materials During Gamma Irradiation," General Electric Company, ANP, TID 15981, undated。 
11. Alexander Goldsmith, et al, "Thermophysical Properties of Solid Materials", Volume III - Ceramics, WADC Report 58-476, November 1960.

12. "Temperature: Its Measurement and Control In Science and Industry", Reinhold Publishing Corporation, 1962.

13. G. L. Fluke, "Tungsten-Rhenium Thermocouple Performance in GTR-13 Test", AGC Report No. 7461:0094, 6 July 1964.

14. J. E。 Perry, Jr. "N-4 Progress Report For Period 21 April through 20 May 1964", Confidential (Title Unclassified)。 LO8 Alamos Scientific

Laboratory, Report No. N-4-2308.

15. Scadron, M.D, Warshowsky, I. "Expimental Determination of Time Constants and Nusselt Numbers for Bare Wire Thermocouples in High-Velocity Air Streams and Analytic Approximation of Conduction and Radiation Errors", NACA TN2599, January, 1952.

16. J. D. Rogers, et al, "Hydrogen Transport Property Calculations", IASL, Reports LA2527 (May 1961) and LA2719 (September 1962).

17. Letter to R. W. Bidstrup (AGC) from Hoskins Manufacturing Company, Detroit, Michigan, 5 September 1963.

18. P. J. Petrozzi, "Properties of Para Hydrogen", Aerojet-General Corporation, Report No. 9050-6S, April 1964. 


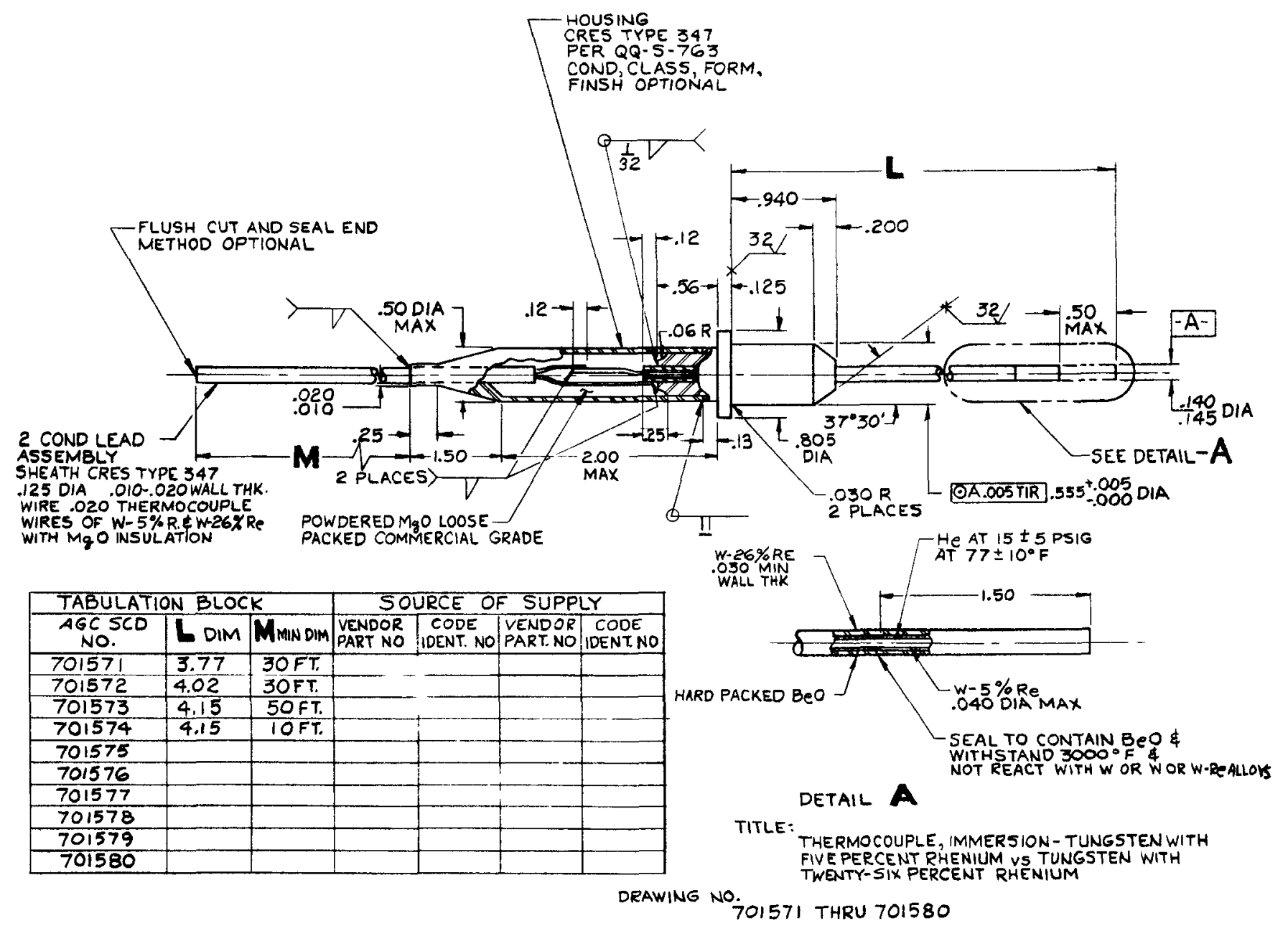

Figure 1

Thermocouple Immension

(Tungsten with 5\% Rhenium vs Tungsten with 26\% Rhenium - Dwgs 701571 thru 701580) 


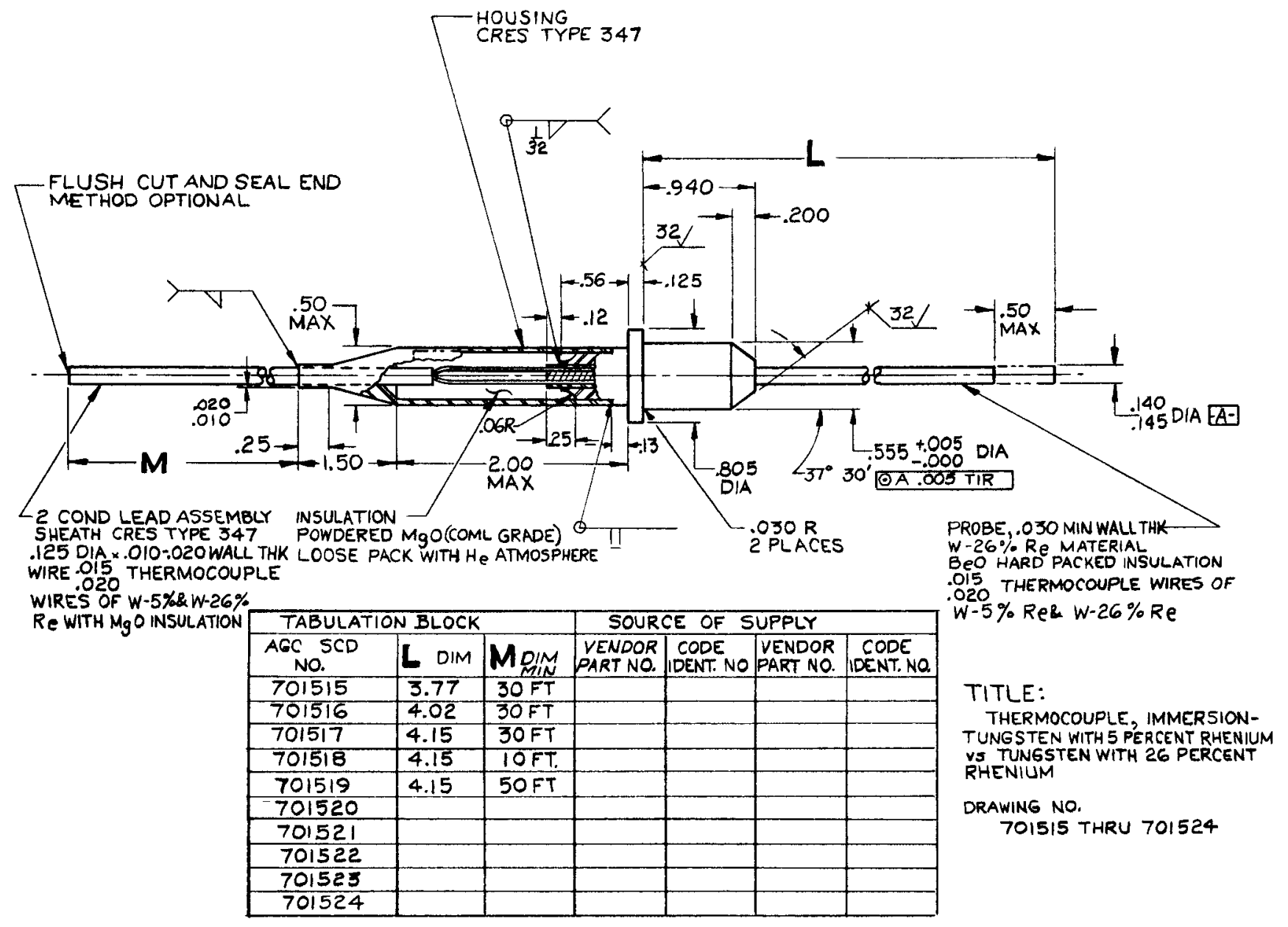

Figure 2

Thermocouple Immension

(Tungsten with 5\% Rhenium vs Tungsten with 26\% Rhenium - Dwgs 701515 thru 701524) 


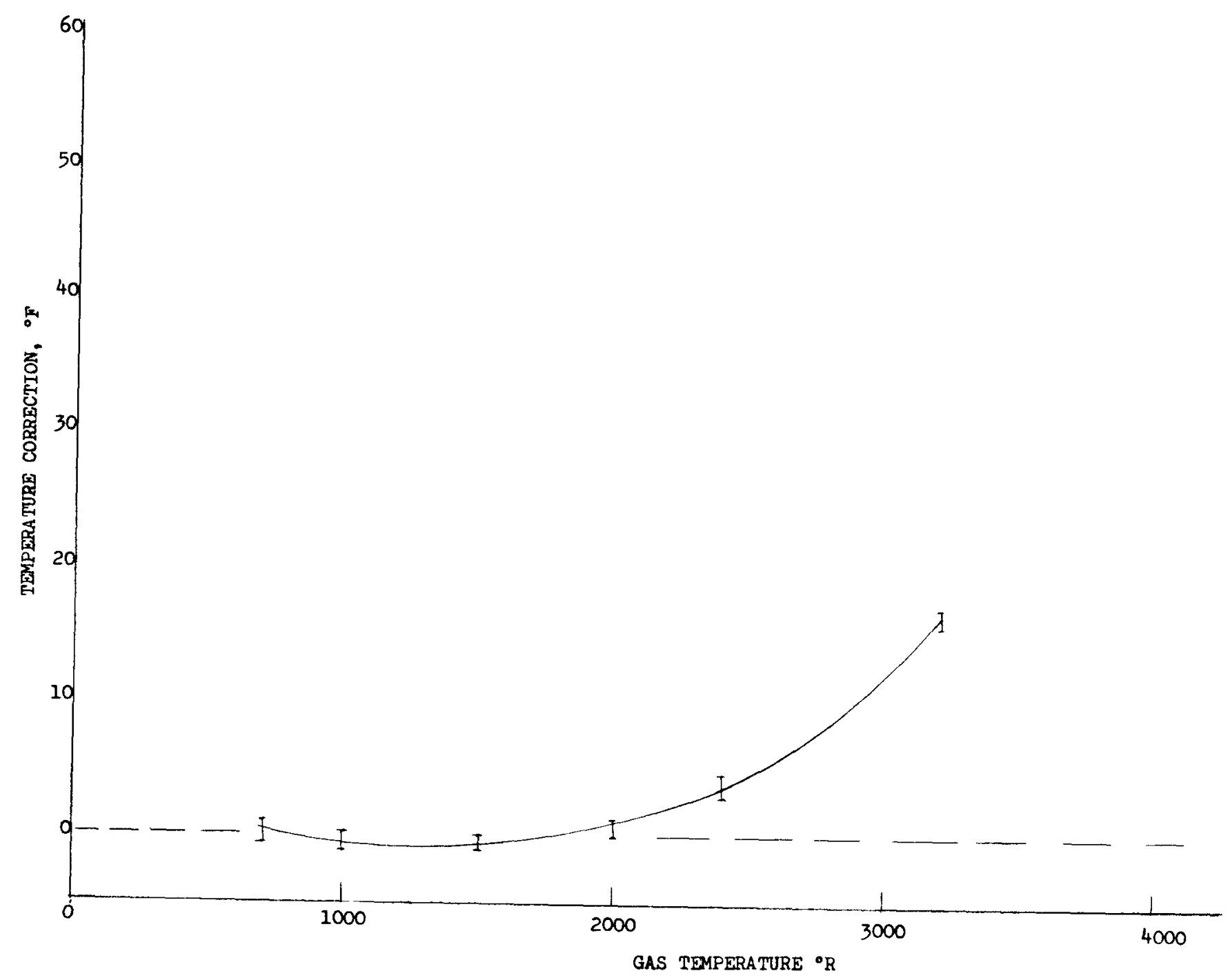

Figure 3

Temperature Correction For BeO w/Re Thermocouples

(NRX-A2 Environment - Nozzle Expansion Ratio = 8.96) 


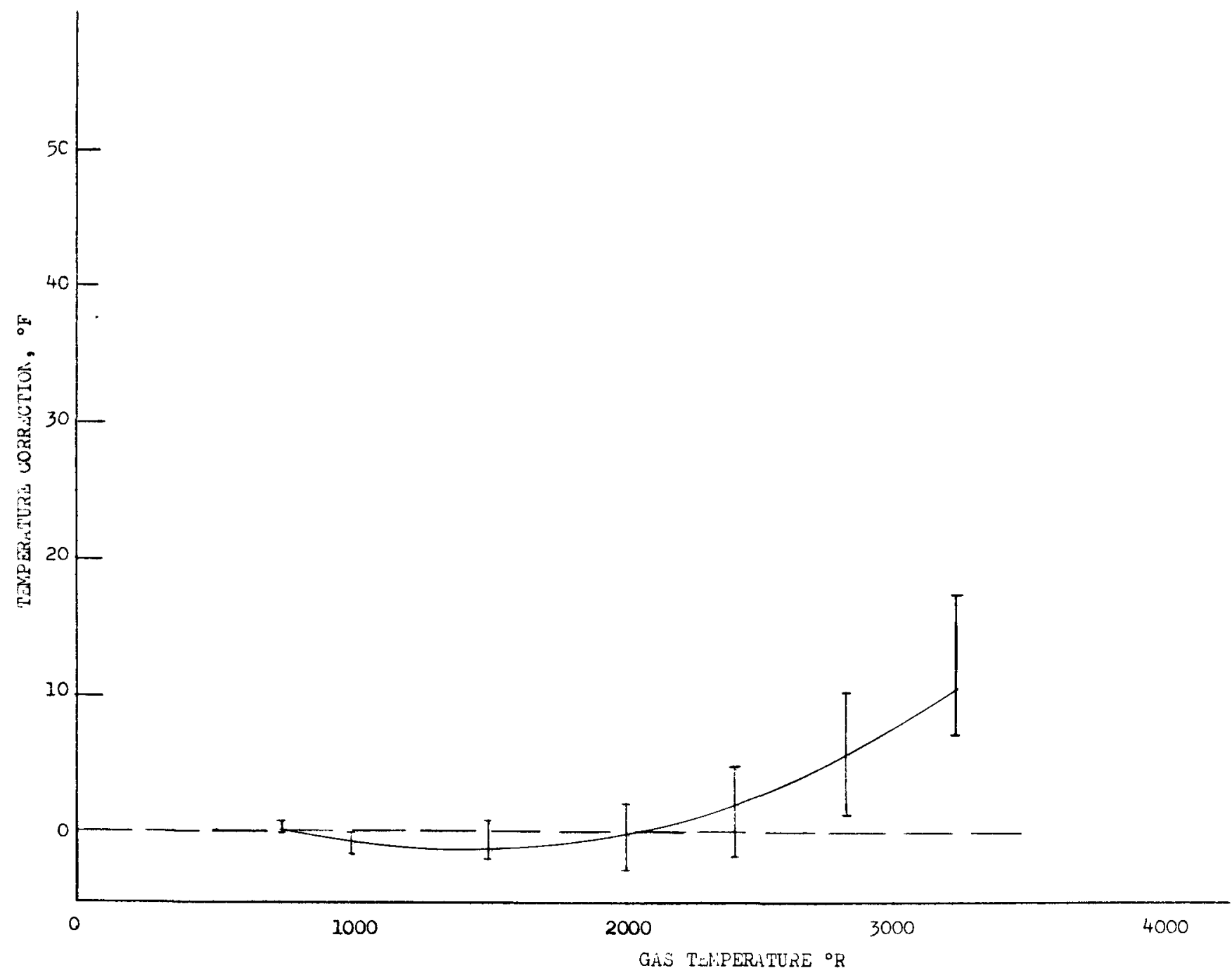

Figure 4

Temperature Corrective for Helium Filled W/Re Thermocouples

(NRX-A2 Environment - Nozzle. Expansion Ratio $=8.96$ 


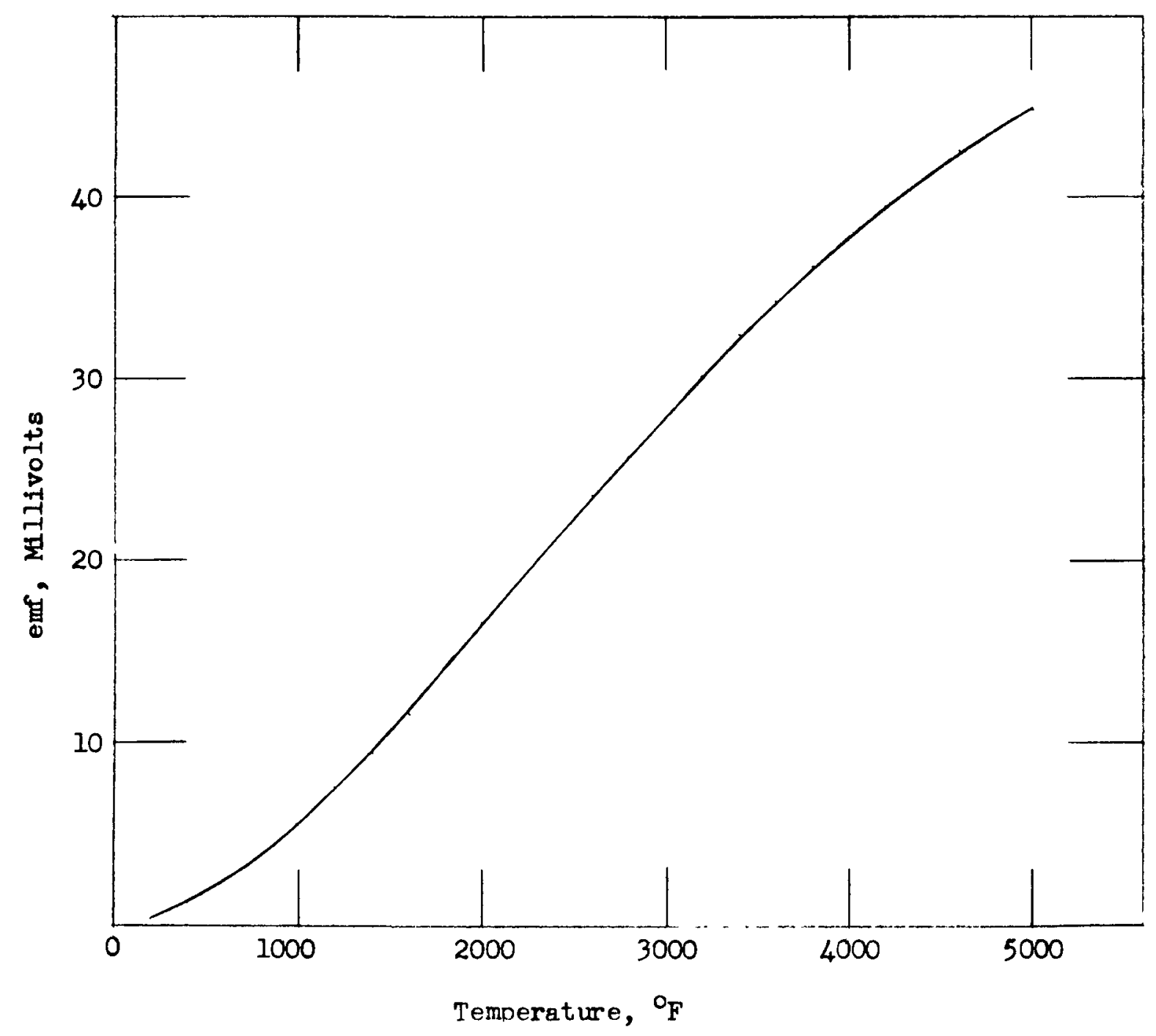

Figure 5

Thermal EMF of Tungsten/26\% Rhenium Thermocouples 


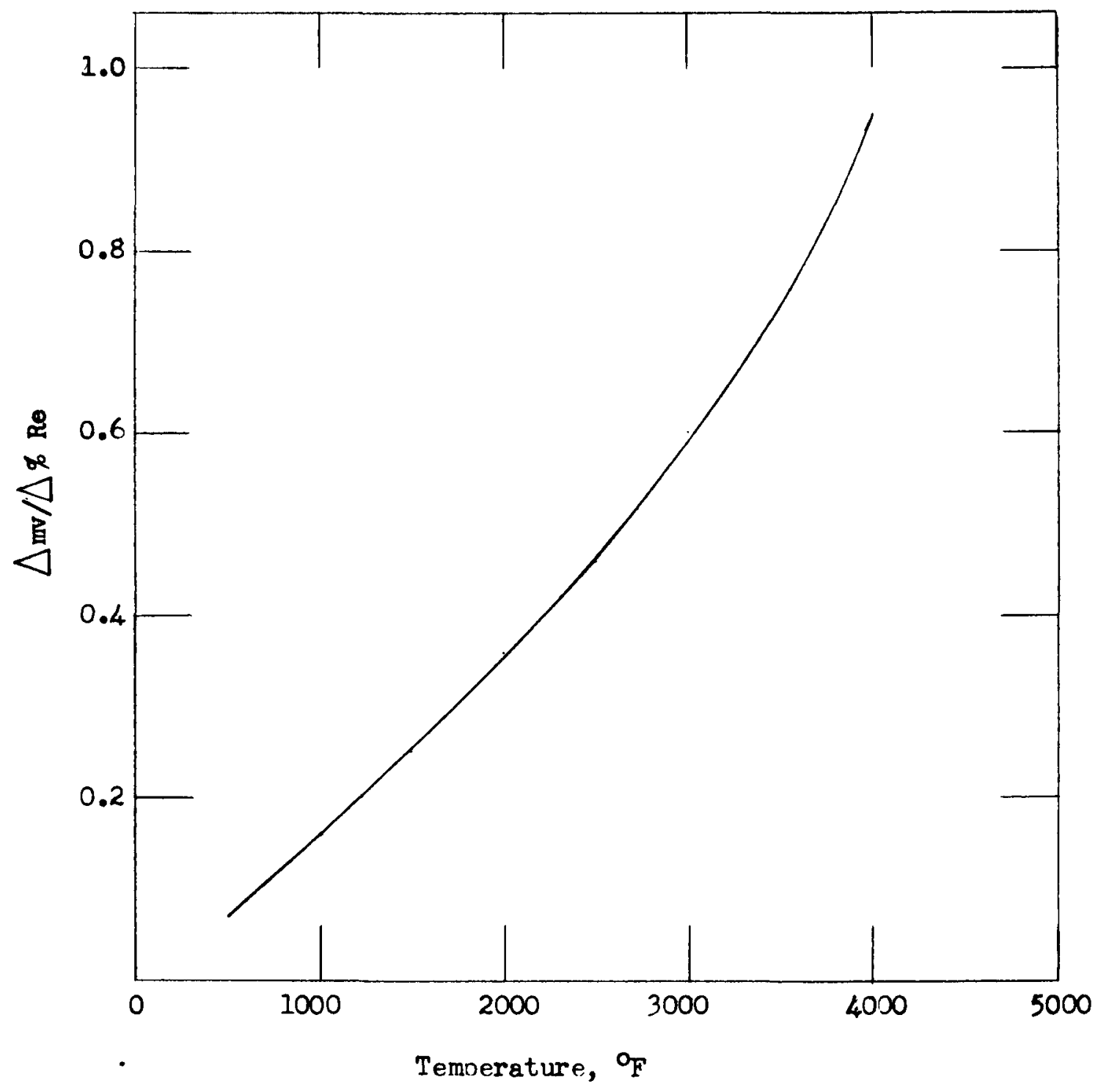

Figure 6

Change in EMF with Percent Change In Rhenium as a Function of Temperature $\mathrm{W} / 26 \%$ Rhenium Thermocouples 

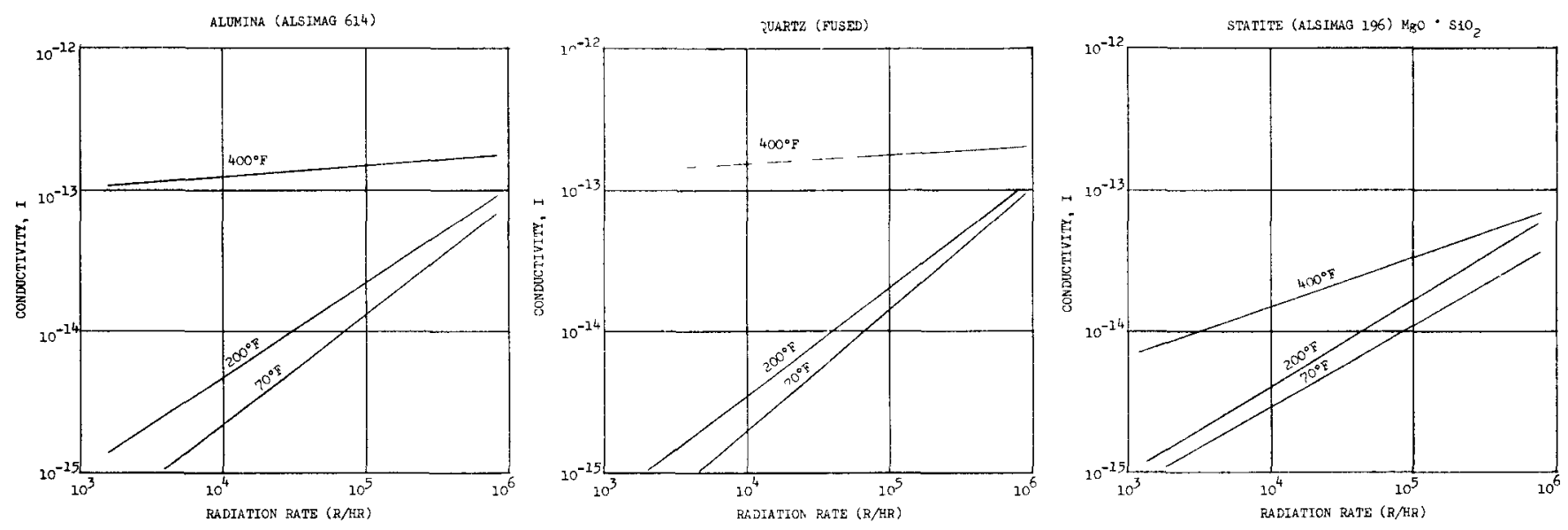

Figure 7

Electrical Conductivity as a Function of Radiation Dose Rate and Temperature 


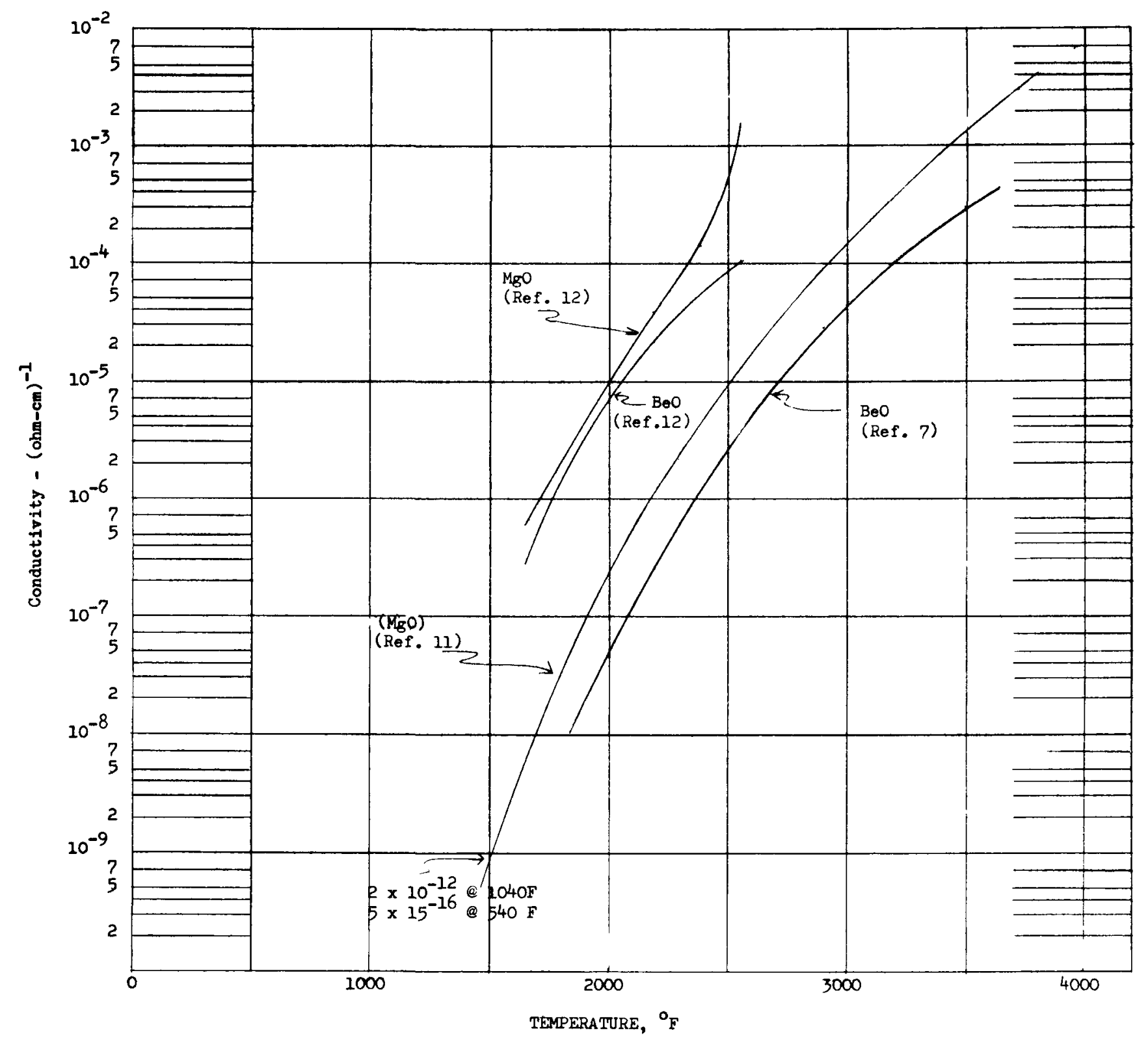

Figure 8

Electrical Conductivities of Ceramic Insulators 
A comparison of heat transfer coefficients evaluated by the expression of Reference 4 and Reference 15 was made. The Scadron, et al expression (Reference 15) for cross-flow heat transfer coefficients is given by

$$
\text { where } \quad \begin{aligned}
& \frac{h D_{0}}{k}=.478 \operatorname{Re}^{1 / 2} \operatorname{Pr}^{0.3} \\
& \operatorname{Re}=\frac{D_{0} G}{\mu}\left(1+\frac{\gamma-1}{2} M^{2}\right)^{-1.69} \\
& \operatorname{Pr}=\text { Prandtl Number }=\mathrm{C}_{\mathrm{p}} \mu / \mathrm{k}, \text { and } \\
& D_{0}=\text { probe diameter }
\end{aligned}
$$

The probe is at an expansion ratio of 8.96 , and the Mach number is 0.07 ; therefore, the factor in the Reynolds number is unity.

The McAdams (Reference 4) heat transfer coefficient is

$$
\frac{h_{0} D_{0}}{k}=\left\{0.32+0.43 \mathrm{Re}^{0.52}\right\} \mathrm{Pr}^{0.3} .
$$

The value of $D_{0}$ was taken as 0.145 -in. and the flow area was taken as $3.67 \mathrm{ft}^{2}$. The thermal transport properties are in Appendix II. 
The following table shows the values of both heat transfer coefficients and the relative temperature decrements of both expressions.

Temp
$\circ \mathrm{R}$

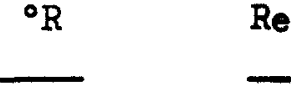

700

$2.323 \times 10^{3}$

1000

1500

2000

2400

2800

3200

4090

$5.371 \times 10^{3}$

$7.429 \times 10^{3}$

$9.107 \times 10^{3}$

$1.031 \times 10^{4}$

$1.119 \times 10^{4}$

$1.207 \times 10^{4}$

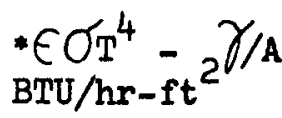

BTU/hr-ft ${ }^{2 / / A}$

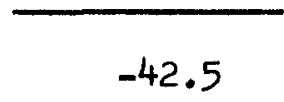

$1.070 \times 10^{4}$
$-188$

38

1738

6376

$1.807 \times 10^{4}$

$3.734 \times 10^{4}$

$1.340 \times 10^{5}$
McAdams

\begin{tabular}{|c|c|}
\hline$\frac{\mathrm{h}}{\mathrm{BTU} / \mathrm{hr}-\mathrm{ft} \mathrm{t}^{2}-{ }^{\circ} \mathrm{F}}$ & $\Delta \mathrm{T}_{\circ \mathrm{F}}$ \\
\hline 266 & -.16 \\
\hline 540 & -.35 \\
\hline 873 & +.04 \\
\hline 1251 & 1.4 \\
\hline 1609 & 4.0 \\
\hline 1914 & 9.4 \\
\hline 2248 & 17 \\
\hline 2540 & 53 \\
\hline
\end{tabular}

NACA TN2599

\begin{tabular}{|c|}
\hline$\frac{h}{B T U / h r-f t^{2}-{ }^{\circ} F}$ \\
\hline 228 \\
\hline 459 \\
\hline 738 \\
\hline
\end{tabular}

1053

1.6

1351

4.7

1606

11

1885

20

2132

- BeO probe

The difference in the expression used for the heat transfer coefficient can cause $10^{\circ} \mathrm{F}$ difference at the highest temperature in the table, which is less than $0.3 \%$ difference.

It should be noted that this agreement is obtained by using the same physical properties. The heating errors are directly proportional to tungsten emissivity and to the 0.7 power of hydrogen thermal conductivity.

The values of hydrogen thermal conductivity are based on curve fit equations of the best available from the literature (Reference 18). The curve-fit data $1 ; \mathrm{r}$ : presented by Los Alamos Scientific Laboratory (Reference 16). The high temperature values are extrapolated, and it would be desirable to have experimental values in the $4000^{\circ} \mathrm{R}$ temperature range. 
The emissivity of tungsten as received and used in probes could be different from the values which are reported in the literature because the values can be affected by the condition of the surface. For example, if the emissivity at $4090^{\circ} \mathrm{R}$ was 0.7 rather than 0.29 the temperature decrement by McAdams expression would be $130^{\circ} \mathrm{F}$. 
APPENDIX II

RESISTIVITY OF TUNGSTEN-RHENIUM ALLOYS

(Reference 17)

\begin{tabular}{c}
$\begin{array}{c}\text { Temperature } \\
{ }^{\circ} \mathrm{F}\end{array}$ \\
\hline 68 \\
200 \\
500 \\
1000 \\
2000 \\
3000 \\
4200
\end{tabular}

HYDROGEN THERMAL TRANSPORT VALUES

(Reference 18)

\begin{tabular}{rccc}
$\begin{array}{c}\text { Temperature } \\
{ }^{\circ} \mathrm{R}\end{array}$ & $\begin{array}{c}\text { Prandtl } \\
\text { Number }\end{array}$ & $\begin{array}{c}\text { Thermal Conductivity } \\
\mathbf{k}\end{array}$ & $\begin{array}{c}\text { Viscosity } \\
\text { Ib/sec-ft }\end{array}$ \\
\cline { 2 - 3 } 700 & .727 & .13 & $.71 \times 10^{-5}$ \\
1000 & .666 & .18 & $.90 \times 10^{-5}$ \\
1500 & .666 & .24 & $1.20 \times 10^{-5}$ \\
2000 & .604 & .32 & $1.45 \times 10^{-5}$ \\
2400 & .546 & .39 & $1.60 \times 10^{-5}$ \\
2800 & .510 & .47 & $1.80 \times 10^{-5}$ \\
3200 & .483 & .54 & $1.95 \times 10^{-5}$ \\
4090 & .447 & .67 & $2.22 \times 10^{-5}$ \\
& &
\end{tabular}

